\title{
Consensus Gentium: Reflections on the 'Common Consent' Argument for the Existence of God
}

\author{
Thomas Kelly \\ Princeton University
}

As the human intellect, though weak, is not essentially perverted, there is a certain presumption of the truth of any opinion held by many human minds, requiring to be rebutted by assigning some other real or possible cause for its prevalence. And this consideration has a special relevance to the inquiry concerning the foundations of theism, inasmuch as no argument for the truth of theism is more commonly invoked or more confidently relied on, than the general assent of mankind.

John Stuart Mill, Theism

\section{Introduction}

I want to take up an argument that might seem a better candidate for contempt than for serious scrutiny. In its crudest and least sophisticated form, the Common Consent Argument for the Existence of God runs as follows:

(Premise) Everyone believes that God exists.

(Conclusion) God exists.

So stated, the argument is not exactly an overwhelming one, suffering as it does from the twin defects of transparent invalidity and the having of an obviously false claim as its sole premise. In a slightly less crude form, the premise of the argument is that almost everyone, or the great majority of humankind, believes that God exists. More generally, proponents of the argument contend that the prevalence of the belief that God exists is itself evidence for the truth of that belief.

The common consent argument has a venerable history. An explicit statement appears as early as Plato's Laws. ${ }^{1}$ A list of prominent thinkers who endorsed some recognizable variant of the argument would include Cicero, Seneca, Calvin, the Cambridge Platonists,

${ }^{1}$ See Book X, 886, where Clinias appeals to the fact that "all mankind, both Greeks and barbarians, believe in them" as one way of proving the existence of the gods. 
Gassendi, and Grotius. ${ }^{2}$ In addition, it was discussed critically by (among many others) Locke, Hume, and Mill. ${ }^{3}$

More recently, the argument has fallen on hard times as an object of philosophical attention. It is seldom taken seriously, even in circles in which arguments for the existence of God are still taken seriously. It is, for example, rarely if ever included among the usual rogues gallery of arguments for the existence of God in anthologies or course syllabi devoted to the philosophy of religion. Among the more sophisticated, book-length critical surveys of such arguments, it is not so much as mentioned in Mackie's The Miracle of Theism, Sobel's Logic and Theism, or Swinburne's The Existence of God. Nor does any reference to it appear in the five hundred and fifty page Oxford Handbook of Philosophy of Religion or in Blackwell's six hundred page A Companion to Philosophy of Religion. In short, although the argument still occasionally appears in popular apologetics ${ }^{4}$, it seems to have virtually disappeared as an object of discussion among professional philosophers.

Perhaps there are good reasons for the more or less complete neglect of the argument among contemporary philosophers of religion, in contrast to the attention that it received from previous generations of thinkers. Nevertheless, despite the apparently anachronistic character of the enterprise, I want to inquire into what might be said for and against a relatively modest version of the argument. In particular, I will be concerned with what I take to be the core thought behind the appeal to common opinion: viz. that the fact that theistic belief is widespread among the human population is itself a significant piece of evidence that God exists, and thus a fact that can boost the rational credibility of theism for those who are aware of it. By my lights, this thought is neither absurd nor obviously correct. Moreover, I believe that some of the issues that arise in connection with it are of

\footnotetext{
${ }^{2}$ For an overview of this tradition, see the useful survey in Edwards (1967).

${ }^{3}$ Locke (1689): Book I, sec. IV; Hume (1757): section XII; Mill (1885 [1998]): 155-160.

${ }^{4}$ See, e.g., Kreeft and Tacelli (1994): 83-85. Even here, however, the argument hardly enjoys pride of place: of the twenty arguments for the existence of God presented by Kreeft and Tacelli, the common consent argument appears nineteenth.
} 
interest not only for the epistemology of religious belief but also for epistemology more generally.

To forewarn the reader: what I have to say on this topic will be quite inconclusive, even relative to the typically inconclusive standards of philosophy. For reasons that I indicate below, I do not believe that we are currently in a good position to say anything definitive about the evidentiary value of appeals to common opinion about the existence of God. (In any case, I am certain that I am not in a position to do so.) What I hope to provide instead is something like a prolegomena to future reflection on this kind of argument, and, perhaps, a small step towards its rehabilitation as a topic of interest among philosophers.

I will begin with some remarks about common consent arguments in general, and then turn my attention to the specific application to the case of theistic belief.

\section{Common consent arguments}

The idea that the sheer popularity of an opinion might provide a respectable reason for thinking that that opinion is true has not found many takers in the Western philosophical tradition. Indeed, one might very well date the beginning of the Western philosophical tradition from Socrates' adamant insistence that the mere fact that certain views and practices are dominant among his fellow Athenians is not itself a good reason for accepting those views and practices. The Socratic injunction to "follow the argument where it leads" is, among other things, an injunction against the uncritical acceptance of prevailing orthodoxies, and a call to consider radical alternatives with an open mind. ${ }^{5}$

Following Socrates' lead, a good part of the subsequent history of philosophy has been devoted to the consideration of radically revisionary views in metaphysics, epistemology, and ethics. In general, it has not been considered a good objection to such views to simply note that they conflict with what is generally believed about what there is, what we know, or what we should do. Significantly, the idea that inconsistency with prevailing opinion is not itself an objection to radical views in philosophy has generally

${ }^{5}$ For a discussion of the relevant intellectual ideal, see Kelly (forthcoming a). 
been accepted not only by proponents of such views, but also by their critics, who have sought to discredit the revisionary views on other, more intellectually respectable grounds. When philosophers argue for and against claims by offering reasons, they do not cite surveys of public opinion. Indeed, for the most part it seems to have been assumed (at least implicitly) that the actual distribution of opinion with respect to a philosophical view has no normative significance whatsoever. ${ }^{6}$

Moreover, it is not simply that standard philosophical practice seems to treat the distribution of opinion among the philosophically unsophisticated masses as normatively irrelevant; the distribution of opinion among the (presumably) more sophisticated philosophers is similarly ignored. For example, perhaps few if any contemporary philosophers are full-fledged skeptics about our knowledge of other minds, in the sense of believing that there is some sound argument that has as its conclusion the claim that 'for all I know, my mind is the only thing of its kind in existence'. ${ }^{7}$ Nevertheless, it would not be considered a good objection to arguments for skepticism about other minds to simply note that such arguments have failed to inspire conviction among the vast majority of philosophers who are acquainted with them. In short, if one were to judge by standard philosophical practice, one might easily be led to the conclusion that contingent, empirical facts about the distribution of opinion among any given group of people are one

${ }^{6}$ A notable exception to this general tendency is the so-called 'common sense' tradition, as embodied by figures such as Thomas Reid and G.E. Moore. Both Reid and Moore regularly returned to the fact that the propositions denied by radical skeptics and revisionary metaphysicians are the objects of universal or near universal belief. Moreover, both men clearly take this fact to have considerable normative significance and to tell against the views in question. For discussion of this aspect of the common sense tradition, see Part I of my Believing with Reason.

${ }^{7}$ Of course, many philosophers have defended skeptical arguments by attempting to show that particular objections to their soundness are misguided, or even that all extant objections are misguided. Some philosophers no doubt believe that we have yet to produce good objections to skeptical arguments, or even that we can reasonably hope to find good objections to skeptical arguments in the future. But all of these broadly sympathetic stances vis-à-vis skepticism are much weaker than genuine skepticism, in the sense specified in the text. 
thing, and considerations relevant to normative questions about what one should believe are an entirely different matter. One might thus be tempted to conclude that any common consent argument is fallacious, on the grounds that it is simply a mistake to treat the fact that people believe as they do as evidence for the truth of what they believe. After all, when one says: "Everyone believes that, but there is simply no evidence that it's true"-surely one does not contradict oneself.

However, it is clear that, at least outside of the philosophy seminar room, we regularly treat the beliefs of others as evidence for the truth of what they believe, revising our own views in the light of what they think, and that (often enough) it is reasonable for us to do so. For example, if I initially believe that our recycling is scheduled to be picked up tomorrow, but I subsequently learn that everyone else on our block thinks that the pick-up is scheduled for today (perhaps I observe that others have already placed their recycling bins on the curb this morning), then I will change my view. Moreover, barring very unusual circumstances, surely this is the reasonable thing for me to do. Similarly, if I perform some non-trivial mathematical calculation but subsequently learn that others who performed the same calculation arrived at a different answer, then I should treat this as evidence of my having made a mistake. Our tendency to treat the views of others as evidence is perhaps most salient in cases of disagreement (when one becomes less confident or even abandons one's original view upon learning that others think something else) or in cases in which one initially holds no view at all about the question at issue (consider cases in which one is otherwise ignorant but defers to the view of an expert upon learning what she thinks). But we also appropriately treat the views of others as evidence that warrants a change of mind in cases in which they agree with views that we already hold. Thus, if I learn that others who performed the calculation arrived at the same answer that I did, then it is reasonable for me to increase my confidence in my original answer in response.

Of course, there are some cases in which it is appropriate to give no weight at all to the fact that others believe as they do, even if the view from which one dissents is a consensus opinion. Indeed, in some cases the appropriate course is to give no weight at all to the consensus opinion, even if one knows that all of the members of the consensus are perfectly reasonable in believing as they do. For example, suppose that my loathing 
of the butler leads me to frame him for crime that he did not commit. Suppose further that I execute my plan impeccably: due to my efforts, the authorities and members of the general public come to possess large quantities of misleading evidence, all of which suggests that the butler is guilty. When I subsequently note with satisfaction the (near) universality of the belief that the butler is guilty, I might very well judge that all of those who hold the belief hold it reasonably. Nevertheless, in these circumstances, I will not treat the fact that everyone else reasonably believes that the butler is guilty as any reason at all to think that this proposition is true.

Notwithstanding such exceptions, the range of cases in which we are prepared to treat the beliefs of others as at least some evidence for the truth of what they believe is impressive. As the examples above make clear, we do so in ostensibly a priori domains such as mathematics as well as when it comes to questions that are straightforwardly empirical, such as those concerning recycling schedules. We often treat the views of others as evidence in cases in which those views are arrived at non-inferentially. (Consider, for example, perceptual judgments: if it looked to me like Horse A crossed the finish line slightly ahead of Horse B, but everyone around me thought that Horse B won the race, then it will typically be reasonable for me to revise my opinion in the direction of the consensus.) But we do the same with respect to inferential judgments that are the deliverances of some piece of reasoning (as in a case mathematical calculation) or based on a body of evidence.

Consider cases in which it is clear that the truth cannot be discerned directly; if it is available at all, one must rely on evidence, broadly construed. In such cases, there are at least two distinct motivations for why one might treat the views of others as evidence. First, others might very well possess relevant evidence that one lacks, or have had relevant experiences that one has not had. To the extent that one regards the others as generally competent interpreters of their evidence and experience, one would expect the probative force of their evidence and experience to be reflected in their beliefs. By giving at least some weight to their beliefs, one gains a kind of indirect access to their evidence and experience. In treating their beliefs as evidence, one is in effect treating their beliefs as a proxy for the first order evidence and experience on which those beliefs are based. In 
this way, one improves the pool of evidence and experience that plays a role in influencing one's own beliefs.

The beliefs of other people often provide our best or only access to relevant evidence: this fact guarantees that the practice of giving weight to the beliefs of others will play a pervasive role in any epistemically well-conducted life. However, if one took the view that this proxy function exhausted the evidential value of the beliefs of others, then one might naturally embrace the following picture: in any case in which one does have direct access to the grounds on which the other person bases her view, one should in effect 'look through' the fact that she believes as she does. One should not give any additional, or independent weight to the fact that she believes as she does, once one has taken into account the grounds that prompt her to believe in this way.

In fact, something like this picture seems to be assumed by many participants in the classical debate over the status of common consent arguments. Here, for example, is Mill:

It may doubtless be good advice to persons who in point of knowledge and cultivation are not entitled to think themselves competent judges of difficult questions, to bid them content themselves with holding that true which mankind generally believe... or that which has been believed by those who pass for the most eminent among the minds of the past. But to a thinker the argument from other people's opinions has little weight. It is but second-hand evidence; and merely admonishes us to look out for and weigh the reasons on which this conviction of mankind or of wise men was founded. ${ }^{8}$

In this passage, Mill significantly underestimates the evidential value of the opinions of other people. For even in the unusual case in which one gains direct access to all of the 'first-hand' evidence on which others base their belief, it will still often make sense to give additional weight to the fact others have responded to that evidence by adopting a certain opinion. For inasmuch as one acknowledges that one is a fallible evaluator of the

${ }^{8}$ Mill (1885 [1998]): 156. Among those who took the common consent argument to have at least some value, a dispute arose as to whether widespread belief in God was itself a reason to believe that God exists or rather merely an 'indication' that such reasons existed. For examples of the latter view, which is similar to Mill's in the epistemic role that it assigns to the opinions of others, see Robert Flint (1877): 349 and Cardinal Mercier (1926): 55. 
relevant kind of evidence (as 'thinkers' surely should), the fact that others have responded to the evidence in a certain way is itself a potentially valuable piece of evidence or information: it is evidence that bears on the accuracy of one's own assessment of the (original, first hand) evidence in this particular case, and thus should affect how confident one ought to be of the view at which one has arrived. ${ }^{9}$

The set of beliefs that a person holds at any given time constitutes a unique perspective on the world. In effect, it says: 'This is how things look from here'. Of course, that perspective is not simply a reflection of how things appear from some point in physical space (as is perhaps suggested by the locational demonstrative 'here'). Rather, it also reflects the individual's past history and experience, the particular ways in which she interpreted or responded to those experiences, her background assumptions and starting points, and much else besides. A proposition that was the object of genuinely universal belief (as opposed to, say, a proposition that was believed by all of the homeowners on my block, or by everyone who had been exposed to the evidence that a certain individual committed some crime) would be a part of any actual perspective on the world. (Of course, it would presumably still be absent from many possible perspectives.)

Even with respect to a universally held belief, one can imagine acquiring evidence that would undermine the potential epistemic significance of the fact that it is universally held. (For example, imagine a possible world in which literally everyone believes that God exists, but in which scientists discover the following fact: because of the character of that world, belief in God has proven evolutionarily advantageous for non-truth-related reasons, and because of this all members of the species are now born with such belief hard-wired into their brains.) However, absent some compelling undermining explanation, we can see why genuinely universal belief that $\mathrm{p}$ would seem to provide impressive evidence that $\mathrm{p}$ is true. For the fact that $\mathrm{p}$ is part of every actual perspective shows that the belief that $\mathrm{p}$ is not the result of idiosyncratic judgment, past history, course of experience, interpretation, or background assumptions or starting points. Rather, it is among the things that are left over when one abstracts away from such idiosyncrasies.

\footnotetext{
${ }^{9}$ For more on this point, see Christensen (2007) and Kelly (2010).
} 
Notwithstanding the intuitive plausibility of such a picture (at least, when it is described in sufficiently broad outline), one might still harbor suspicions about the idea that the mere belief that $p$ (no matter how widespread) could by itself ever amount to fullfledged, independent evidence that $\mathrm{p}$ is true. For suppose that there is originally no evidence whatsoever that $\mathrm{p}$ is true, but that large numbers of people nevertheless unreasonably come to believe it for bad reasons, or for no reasons at all. If widespread belief in $p$ constitutes genuine evidence that $\mathrm{p}$ is true (at least, in the absence of the availability of some undermining explanation), then those who baselessly believe $p$ would seem to have magically brought evidence for $\mathrm{p}$ into existence merely by believing it in the absence of any evidence. Here we seem to have gotten something from nothing, and the way seems clear for all sorts of dubious bootstrapping maneuvers, by which illsupported views come to be reasonably believed merely by once having been believed unreasonably.

However, although this phenomenon can look strange when viewed in certain lights, it is a genuine one. For example, suppose that the following improbable event were to occur: every person in our group happens to make exactly the same mistake while performing some non-trivial mathematical calculation, and thus independently arrives at the same mistaken answer. At the moment we learn what the others think, each of us should increase his or credence that the mistaken answer is correct. In this case, the beliefs of others constitute genuine (albeit misleading) evidence for the mistaken conclusion. Nevertheless, there is a clear sense in which, prior to becoming aware of what the others think, none of us had a legitimate basis for believing as we did. After all, given that the case involves a mathematical mistake, not only do the truths from which we reason fail to support the answer at which we arrive, but they literally entail the falsity of that answer. The fact that a proposition is widely believed can constitute strong evidence that that proposition is true, even if there would be no evidence that it is true in the absence of its being believed.

In various ways then, our practice of treating the beliefs of others as evidence serves as a crucial epistemic resource and check on our own thinking. More specifically, in many cases - although certainly not all—when one finds oneself out of step with some consensus, it is reasonable to adjust one's own view in the direction of the prevailing 
view. Thus, at least one natural criticism that someone might make of common consent arguments in general - that to cite the fact that a large number of people believe that $\mathrm{p}$ as evidence for $\mathrm{p}$ is a kind of category mistake - misses the mark. Moreover, notice that with respect to the specific case of religious belief, many atheists and agnostics will also insist that the actual distribution of opinion is normatively significant. So, for example, many atheists and agnostics will think that the diversity of theological beliefs among theists (i.e., the fact that the theists are divided among Muslims, Jews, Christians, and others) provides evidence against the theists' more specific theological commitments.

Consider some cases in which, intuitively, I am justified in believing some proposition because I know that that proposition is believed by all or almost all of the members of some salient group. For example, if a non-trivial math problem is given to ten individuals, then, even if I myself am ignorant of the parameters of the problem, I will typically be justified in believing that the correct answer is ' 138 ' upon learning that that is the answer that each of the ten came up with. And the same will be true, presumably, if only eight or nine of the ten came up with that number.

Suppose next that I am one of the ten individuals who is given the problem. In a case in which I learn that the other nine arrived at the same answer that I did, I should increase my confidence in that answer. On the other hand, if I learn that the other nine arrived at some different number, it will typically be reasonable for me to give up my original belief and conclude that their answer is correct. Moreover, notice that this will typically be the rational course even if I am the most reliable of the ten individuals when it comes to the relevant kind of math problem, and I know that I am. For even if I have compelling evidence (perhaps on the basis of our past track records) that I make fewer mistakes than the second most reliable person in the group, it will typically be much more likely that I've made a mistake in this case, than the others have managed to mistakenly arrive at the same wrong answer. ${ }^{10}$

\footnotetext{
${ }^{10}$ Notice that the relevant comparison is not the probability that I've made a mistake versus the probability that each of the nine others made some mistake, but rather the probability that each of the nine made a mistake given that they arrived at the same answer. In a case in which I know that we each arrived at our answers independently, the last probability might very well be astronomically low, even if each of the nine individuals frequently makes mistakes.
} 
How should we understand the inference from 'The dominant opinion in the group is p' to the truth of p? I suggest that we construe the inference as an inference to the best explanation. ${ }^{11}$ In general, I am justified in concluding that $\mathrm{p}$ is the case on the basis of the fact that $\mathrm{p}$ is the dominant opinion in the group only if the truth of $\mathrm{p}$ is part of the best explanation of the fact that $\mathrm{p}$ is the dominant opinion in the group. That $\mathrm{p}$ is the case and most of the group has managed to pick up on this is one among many potential explanations of the fact that $\mathrm{p}$ is the dominant opinion: roughly, it is the kind of thing that would actually explain why $\mathrm{p}$ is the dominant opinion if it were true. ${ }^{12}$ To say that it is the best potential explanation is to say that it scores higher than any other, rival potential explanation when evaluated by the usual criteria of plausibility, fit with background knowledge, explanatory power, simplicity, and so forth. Of course, even if it is in fact the best potential explanation with respect to these criteria, that does not guarantee that it is the true or actual explanation: inference to the best explanation, like inductive inference more generally, is fallible even when impeccably performed. This is as it should be, for to claim that the truth of $\mathrm{p}$ is (part of) the best explanation for why $\mathrm{p}$ is the dominant opinion is not to deny the obvious fact that the convergence of opinion regarding $\mathrm{p}$ is consistent with the falsity of $\mathrm{p}$. (For example, perhaps all of those who arrived at the number ' 138 ' just happened to make exactly the same mistake in their calculations.) Rather, it is to say that no potential explanation of the convergence that fails to mention the truth of $\mathrm{p}$ is as good as some potential explanation that does invoke the truth of $\mathrm{p}$.

The attractiveness of construing the relevant reasoning as an inference to the best explanation is perhaps most clear in cases in which the relevant inference is not warranted. For example, suppose that I know that although all of the other members of the group arrived at some specific answer other than the one at which I arrived, only one

\footnotetext{
${ }^{11}$ On inference to the best explanation, see especially Lipton (1991) and White (2005). A seminal paper is Harman (1965).

${ }^{12}$ On potential versus actual explanations, see Lipton (1991): 56-66. As Lipton notes, the equation between 'true potential explanation' and 'actual explanation' is not quite right: being a true potential explanation seems to be a necessary, but not quite sufficient condition for being an actual explanation. Sufficiency fails in cases of (e.g.) causal preemption. The existence of such cases will not make a difference in what follows.
} 
person performed the calculation on his own: the rest either copied their answer from him, or copied from someone who copied from him. In that case, the 'truth explanation' is trumped; there is no need to invoke the truth of the claim that 138 is the correct answer in accounting for why that belief is dominant in the group, for we can account for its dominance in a way that does not appeal to its truth. Given that I am aware of how this convergence came about, the numbers drop out: I should give no more credence to ' 138 ' than I would upon learning that that was the answer arrived at by the individual who worked on the problem on his own. And if I know that I am more reliable than any other individual in the group, I should give less credence to that answer than to the one at which I arrived. Here, being greatly outnumbered counts for nothing.

More generally, the epistemic significance of the existence of consensus with respect to a given issue depends on how the existence of that consensus is best explained. (When in The Structure of Scientific Revolutions Thomas Kuhn attributed the ability of the natural sciences to achieve consensus to the fact that its practitioners are commonly educated into the reigning paradigm, many took this thesis as potentially undermining the epistemic significance of widespread agreement within the natural sciences.) Some explanations of a prevailing consensus might reinforce its status as an indication of truth, other explanations might undermine its status as such.

3. Common consent arguments for theism: some comments on the traditional debate

As a historical matter, the traditional arguments for the existence of God have often been offered as "proofs", where it is a necessary condition for an argument's being a genuine proof that its premises entail its conclusion. Judged by this standard, any version of the common consent argument is a clear failure, for even if there is universal agreement that $\mathrm{p}$ is the case, that does not entail that $\mathrm{p}$ is the case. This obvious point is generally conceded by proponents of the argument, who typically make weaker claims on its behalf. For example, Kreeft and Tacelli acknowledge that widespread belief in God is consistent with the truth of atheism, but claim that, in the absence of a compelling debunking explanation of such belief (which they do not believe is in the offing), believing in God is more reasonable than not believing (1994: 84). 
I think that the friend of the common consent argument should aim for a significantly more modest conclusion. The friend of the argument should argue, not that widespread belief in God renders such belief reasonable all things considered, but rather that widespread belief in God is a significant piece of evidence in favor of the truth of that belief. This latter claim, while ambitious and controversial, is nevertheless much weaker than the former. For even if widespread belief in God is a significant piece of evidence for theism - indeed, even if it is sufficiently strong to justify theistic belief in the absence of any other evidence--it does not follow that it is sufficient to do so once all of the evidence is taken into account. After all, insofar as what it is reasonable to believe about some question is determined by one's evidence, what is relevant is one's total evidence, as opposed to some particular piece of evidence that one possesses, or some proper subset of one's total evidence. And of course, one might very well have other evidence that bears on the question of whether God exists, quite apart from one's knowledge of what others believe about this question. For example, many have thought that the existence of evil provides powerful (perhaps even conclusive) evidence against the existence of God; if so, anyone who is aware that the world contains evil has a powerful piece of evidence against the existence of God. Some have thought that certain large-scale structural features of the world constitute significant evidence in favor of the existence of God; if so, then anyone who is aware of those features possess evidence for the existence of God in addition to whatever evidence (if any) is provided by the fact that others believe as they do. Even if it is true that facts about the distribution of opinion constitute genuine evidence that bears on the question of God's existence, it would be a mistake, I think, to suppose that this is the only evidence that is relevant, or that it swamps any other evidence into insignificance. ${ }^{13}$

\footnotetext{
${ }^{13}$ In fact, on some views about how we should take the views of others into account, facts about the distribution of opinion do frequently swamp other kinds of evidence, in the sense that they suffice to fix the facts about what one is rationally required to believe. I believe, and have argued at some length, that such views are too strong to be defensible. See my $(2005,2010$, forthcoming b). Suffice it to say that, if I am wrong and such views are correct, common consent arguments for philosophically interesting conclusions might have even more potential than I credit them with here.
} 
Once this point is taken on board, space is cleared for the following possibility: an atheist or agnostic might agree with a proponent of the common consent argument that widespread belief in God is evidence for theistic belief but insist that, nevertheless, belief in God is unreasonable given the kind of evidence that is typically available to would-be believers. Such an atheist or agnostic might agree that a careful statement of the common consent argument results in an inductively strong argument (to employ terminology that lacks the currency it once had), but nevertheless deny that belief in God is reasonable on the grounds that the premises of any such argument will fail to encapsulate the total evidence that is available to would-be believers. (And, the atheist or agnostic will add, once premises encoding the missing information are added, the resulting argument will not be inductively strong.) Conversely, a theist might hold, alongside many atheists and agnostics, that the actual distribution of opinion with respect to God's existence is significant evidence against the existence of God, but maintain that such belief is nevertheless justified on balance, once all of the relevant evidence is taken into account.

Of course, many people do not believe that God exists. Indeed, the rise of secularism in Western Europe was surely a primary cause for the decline in popularity of the common consent argument among religious apologists. Where formerly religious conflict had been almost entirely between adherents of rival theistic traditions who at least shared an underlying belief in God, theism itself came to seem controversial. ${ }^{14}$ In such a context, appeals to the 'consensus' that God exists seemed increasingly lame.

Does the evident existence of significant numbers of non-believers fatally undermine the argument? It is true that many classic presentations of the argument place great emphasis on the putative fact that belief in God is in some sense universal. In response to the apparent existence of non-believers, various strategies were adopted. The most extreme of these was to insist that the apparent existence of non-believers is merely apparent. According to this line of thought, even those who sincerely professed not to

\footnotetext{
${ }^{14}$ Of course, there had always been atheists and agnostics. But at various times and places, their relative invisibility had been such as to make non-belief seem like an extremely marginal (and therefore, practically insignificant) phenomenon. In Western Europe, this had certainly ceased to be true by the middle of the nineteenth century. For a good overview of the relevant history, see Chadwick (1990).
} 
believe in God at some level really did so; such belief would manifest itself in (e.g.) sufficiently extreme circumstances. ${ }^{15}$ (Compare the old saying that "There are no atheists in foxholes".) Another extreme response was to concede the existence of genuine atheists but to discount their significance on the grounds that they were too anomalous to matter, where 'anomalous' was given a normative spin. Thus, in the course of putting forth his own version of the argument, Pierre Gassendi minimized the significance of atheists on the grounds that such people were either "intellectual monstrosities" or "freaks of nature". ${ }^{16}$

No response along these lines is respectable. If the common consent argument depended on a claim to the effect that everyone is 'really' a theist in some sense, or that atheists and agnostics are defective human beings, then it would be unworthy of discussion. In fact, however, neither the interest nor the plausibility of what I have identified as the core thought behind the traditional argument—viz., that widespread belief in God provides evidence for the truth of that belief - presupposes any such claim. After all, in many cases, the fact that a substantial majority of some group shares an opinion is strong evidence that it is true, even if a significant part of the group does not share (and even explicitly rejects) that opinion. Consider then:

The datum: A strong supermajority of the world's population believes that God exists.

In the United States Senate, sixty out of one hundred votes constitutes a supermajority; I use the phrase 'strong supermajority' to capture the fact that, by conventional estimates, the percentage of the world's population that believes in God

\footnotetext{
${ }^{15}$ For a view of this kind, see Hodge (1871).

${ }^{16}$ Quoted in Edwards (1967: 252). A different kind of universality claim that was sometimes put forward was the following: although there are some non-believers, belief in God is found in every civilization, and moreover, in each civilization, the believers significantly outnumber the non-believers. We might think of this as the Electoral College version of the common consent argument.
} 
greatly exceeds sixty percent of the total. ${ }^{17}$ While I will raise a question about the datum towards the end of this paper, I will for the most part simply assume that it is true in order to inquire what might follow from it. We can thus restate the core idea behind the common consent argument as follows:

The datum constitutes significant evidence in favor of the proposition that God exists.

In addition to the rise of secularism, there is a second reason for the argument's decline in popularity that we should pause to consider: to a large extent, discussion of the argument was simply swallowed up by the great controversy between empiricists and rationalists. ${ }^{18}$ Historically, the argument was closely associated, in the minds of both its proponents and its critics, with the doctrine of innate ideas. Typically, proponents of the argument claimed that the (near) universality of religious belief was due to the fact that the concept of God, and belief in His existence, were part of the innate furniture of the human mind. ${ }^{19}$ Traditional versions of the argument thus frequently came under fire in the context of more general empiricist critiques of innateness claims. For example, in the Essay Concerning Human Understanding, Locke explicitly argued that the idea of God (and therefore, belief in God) is not innate. For his part, Mill (1885[1998]:155-160) argued that even if it were conceded that belief in God is innate, this would not provide any respectable reason for thinking that that belief is true. As strong innateness claims increasingly fell out of favor among philosophers, so too did consensus gentium arguments.

${ }^{17}$ See, e.g., the data compiled in Zuckerman (2006). Zuckerman (a sociologist of religion and an atheist, one of whose avowed purposes is to show that non-belief is more common than is typically claimed) estimates that approximately $88 \%$ of the world's population believes in God.

${ }^{18}$ On this point, see O’Briant (1985):73-74.

${ }^{19}$ Notice how this picture fits well with the popular theme that atheists are defective human beings: such people were either born lacking a crucial part of our natural endowment, and thus suffered from a kind of birth defect, or else had become so corrupt that they had lost their grip on what is essentially given to any normal human mind. 
However, the core thought behind the common consent argument does not presuppose that belief in God is innate, any more than it presupposes the universality of that belief. Indeed, I believe that in some respects the argument is better off if belief in God is not innate, but rather acquired after experience of the world. Consider two possible worlds; in each, belief in God is universal among all adult human beings. The difference between the two worlds is the following. In the first world, all human beings are born with the belief that God exists; such belief is simply part of the innate endowment of the human mind. In the second, no one is born with the belief, but everyone acquires it by the time they reach adulthood in response to their experiences of the world. Suppose further that, in each world, the inhabitants know that all adults in their world believe that God exists, and also the manner in which this convergence came about. We can then ask: in which of the two worlds should the inhabitants be more impressed by the convergence of opinion? Although it presumably will matter a great deal how the details are filled in, I believe that a strong case can be made that, all else being equal, inhabitants of the second world have stronger evidence that God exists than inhabitants of the first world. For notice that, in a world in which everyone is simply born believing in God, there will be certain relatively attractive, debunking (i.e., non-truthinvoking) explanations of the fact that everyone believes in God that are simply not available in the other world. Consider, for example, the kind of evolutionary explanation gestured at in Section 2 above. Explanations of this general form are genuine competitors to truth-invoking explanations in the first world, but are non-starters in the second. More generally, and despite what many participants on both sides of the traditional debate seemed to think, the core thought behind the common consent argument does not presuppose that religious belief is innate as opposed to acquired. ${ }^{20}$

In response to the claim that the datum provides confirming evidence for the proposition that God exists, the critic of the argument might offer a naturalistic, debunking explanation of the datum in the style of Marx, Freud, Durkheim, Weber, or their contemporary successors. Critics of such naturalistic explanations sometimes complain about their speculative character, and the fact that they are typically not

${ }^{20}$ Cf. O’Briant (1985): 74-75. 
accompanied by much in the way of independent evidence. ${ }^{21} \mathrm{I}$ believe that there is considerable truth to such charges, but also that in the present dialectical context they are not wholly to the point. Again, the proponent of the common consent argument claims that the datum confirms the hypothesis that God exists because the latter is (part of) the best explanation of the former. However, the extent to which a piece of evidence confirms a given hypothesis can be significantly affected by the mere presence of alternative hypotheses in the field, even in the absence of any reason for preferring those alternative hypotheses. In general, how strongly a given piece of evidence confirms a hypothesis is not solely a matter of the intrinsic characters of the evidence and the hypothesis. (Nor is it solely a matter of their intrinsic characters together with one's background theory of how the world works.) Rather, it also depends on the presence or absence of plausible competitors in the field. It is because of this that the mere articulation of a plausible alternative hypothesis can dramatically reduce how likely the original hypothesis is on the evidence in question. ${ }^{22}$ Thus, the provision of a plausible debunking explanation of the datum can drain the support that it would otherwise lend to the hypothesis that God exists even in the absence of independent empirical evidence to think that the debunking explanation is correct.

21 See, e.g., Kreeft and Tacelli, (1994: 84).

${ }^{22}$ Consider a historical example that is often thought to illustrate this normative phenomenon. Many organisms manifest special characteristics that enable them to flourish in their typical environments. According to the Design Hypothesis, this is due to the fact that such organisms were so designed by an Intelligent Creator (i.e., God). The Design Hypothesis is a potential explanation of the relevant facts: if true, it would account for the facts in question. How well-supported is the Design Hypothesis by the relevant evidence? Plausibly, the introduction of the Darwinian Hypothesis as a competitor in the nineteenth century significantly diminished the support enjoyed by the Design Hypothesis. That is, even if there had been no reason to prefer the Darwinian Hypothesis to the Design Hypothesis, the mere fact that the Design Hypothesis was no longer the only potential explanation in the field tends to erode (to some extent at least) how much credence the Design Hypothesis merits on the basis of the relevant considerations.

The general point was forcefully pressed by Hilary Putnam in the 1960s as a reason for doubting that Carnap's vision for inductive logic was a well-conceived research program; the relevant papers are collected in his (1975). A good discussion of the issue is Earman (1992), chapter 7. 
Of course, the proponent of the common consent argument might question just how plausible the debunking explanation on offer really is. (After all, just how plausible is Freud's claim that belief in God is rooted in universal dissatisfaction with our own actual fathers qua protectors?) In response, one who offers the naturalistic explanation might point out that what is at issue is the comparative plausibility of hypotheses, and it is not at all obvious why we should think that 'the truth hypothesis' sets a high standard in that regard. $^{23}$

Still, I believe that once things have reached the point of comparing competing hypotheses in this way, considerable ground has been conceded to a proponent of the common consent argument_ - perhaps more ground than a critic of the argument should feel comfortable conceding. At this point, the proponent of the argument is in a position to go on offense: he can raise doubts about the plausibility of the debunking explanation on offer, and attempt to provide independent reasons for thinking that it is false. If it is conceded that the only reason why the datum does not provide evidence for theistic belief is because there is some formidable competing explanation in the field, then to the extent that doubt is cast on that explanation on independent grounds, one's credence in the 'truth hypothesis' - and therefore, in the proposition that God exists-- should increase accordingly.

\footnotetext{
${ }^{23}$ Indeed, it might be argued that until the defender of the common consent argument offers some story about the mechanism by which the putative truth that God exists is grasped, she has not yet offered a genuine potential explanation of widespread belief in God. (According to this line of thought, to simply appeal to the putative fact that $\mathrm{p}$, along with an unspecified ability of many individuals to somehow hit upon that truth is not yet to have offered a genuine potential explanation of why $\mathrm{p}$ is widely believed.) As a general matter, I believe that this demand for the specification of a mechanism is misplaced. After all, as is clear from the philosophy of mathematics, we do not currently possess a good story about the mechanism by which individuals recognize the fact that $2+2=4$. Nevertheless, it seems that we can be reasonably confident that the correct explanation of why $2+2=4$ is (almost) universally believed invokes or entails the fact that that proposition is true. That having been said, there is no question that the specification of a plausible mechanism for theistic belief would greatly strengthen the hand of a proponent of the argument.
} 
Suppose that one does not have much confidence in any particular naturalistic explanation of theistic belief that has actually been proposed, or even in the disjunction of all such explanations that have been proposed thus far. How might one nevertheless resist the suggestion that the datum confirms the proposition that God exists? In the final section of the paper, I want to explore some strategies for minimizing the significance of the datum that do not depend on the availability of formidable naturalistic explanations of religious belief. The strategies that I consider here certainly do not exhaust the possible strategies that one might pursue, nor do I have anything particularly definitive to say about them. I focus on these strategies largely because I believe that each one raises deep and interesting philosophical issues.

4. Some strategies for minimizing the significance of the datum

(i) The datum is relatively insignificant, because the poorly informed/unenlightened/unsophisticated (etc.) are overrepresented among the theists.

The first line of response that I would like to consider proceeds from the correct observation that properly taking into account the opinions of others is not simply a matter of counting heads. Consider a possible norm of belief revision according to which what one should believe about a given question is determined by a kind of hypothetical vote among everyone in the world who has an opinion about that question. Such a radically egalitarian norm is clearly sub-optimal. Among its weaknesses is that it in effect enjoins us to throw out valuable information: with respect to a given question, we might know that some are in a better position to judge than others in virtue of being better informed, or for some other reason. To the extent that one has information that bears on comparative reliability, one should adjust the weight that one gives to the opinions of others accordingly. ${ }^{24}$

\footnotetext{
${ }^{24}$ And of course, this includes the possibility of giving zero or even negative weight to the views of some. (The last option will be appropriate in cases in which one has evidence that suggests that someone is an anti-expert with respect to a given domain; on the phenomenon of anti-expertise, see Sorensen (1988): 386-397 and Egan and Elga (2005)).
} 
Thus, someone attempting to minimize the significance of the datum might claim the following: even if believers greatly outnumber non-believers in absolute terms, the nonbelievers, considered as a group, are better informed, or more sophisticated, or enjoy some other cognitive advantage. (Presumably, many non-believers think exactly this.) Indeed, someone might very well think that the relevant disparities are sufficiently pronounced that, once opinions are properly weighted, taking into account the distribution of opinion bolsters the case for atheism as opposed to theism, and it is thus the non-believers who should take comfort in the numbers.

Of course, many theists would take issue with any such assumptions. Perhaps unsurprisingly, I will not attempt to say anything here about the respective intellectual merits of believers and non-believers as classes of people, or even whether such very general comparisons are sensible at all. Instead, I will emphasize an important but frequently neglected truth of epistemology that we should bear in mind when assessing strategies of this general kind.

The point is the following: in many cases, even if one knows with certainty that one is in a superior position to judge than another person - say, because one knows that one is better informed, and that one has responded to one's superior evidence impeccably - it is still rationally incumbent upon one to give significant weight to the other person's differing opinion and revise one's own view in response. Here is a toy example that makes the point cleanly:

THE URN: An urn contains a large number of marbles, some of which are black, the rest of which are white. You and I are charged with estimating the ratio of black to white balls in the urn; we base our estimates on observing draws with replacement. Before you enter the room, I observe ten draws and arrive at an estimate. I then leave the room; you enter, and observe the next six draws. Later, I discover that your estimate of the proportion of black marbles in the urn is significantly lower than mine.

In this case, it is uncontroversial that my estimate is significantly better informed than yours. Nevertheless, once I learn what you think, I should revise my estimate of the proportion of black balls downwards. (Certainly, it would be a mistake for me to stick to my guns on the grounds that you are in a worse position to make a judgment than I am, even though that is clearly true.) Of course, inasmuch as my original estimate was better 
informed than yours, this should be reflected in my revised estimate, which should be closer to my original estimate than to yours. Notice, however, that as more people who have made at least partially non-overlapping observations weigh in, my own original estimate counts for less and less in determining what it is reasonable for me to believe. At some point, it will be swamped into insignificance, even if all of the other estimates are based on significantly worse evidence than mine.

Significantly, the lesson that even the opinions of those who are in an objectively worse position to judge often make a difference, indeed a decisive difference, to what it is reasonable for one to believe generalizes far beyond such toy cases. In general, individuals are much more likely to defer to the opinions of perceived experts than to the cumulative judgments of large numbers of non-experts, even though the latter is frequently the better strategy (even in cases in which the perceived experts really are experts, in the sense that they are in a better position to judge than any individual member of the group of non-experts). ${ }^{25}$

At one time, the most popular program in the history of American television was the game show Who Wants to be a Millionaire? Contestants attempted to win a million dollars by answering a series of multiple choice questions in ascending order of difficulty. As an added wrinkle, contestants were also given a limited number of "lifelines" or opportunities to consult other sources when their own judgment about a given question left them uncertain. One such lifeline consisted of the opportunity to poll the studio audience, a relatively large group of ordinary people. An alternative lifeline allowed the stumped contestant to "phone a friend", and ask an individual whom she had selected before the show as the person of her acquaintance most likely to correctly answer the kind of question that she would encounter. An interesting fact that soon became apparent to regular viewers of the show was this: in general, the strategy of polling the studio audience was vastly superior to the strategy of consulting the expert-

\footnotetext{
${ }^{25}$ This is a main theme of James Surowiecki's The Wisdom of Crowds (2003), which provides much impressive evidence of the phenomenon.
} 
friend. ${ }^{26}$ For the typical contestant, deferring to the cumulative judgment of the random group was a better bet than deferring to the person she considered most trustworthy from among her circle of acquaintances.

The cumulative opinion of a large number of people often provides significant evidence even when it conflicts with the opinion held by a comparatively smaller group of people who are in a better position to judge. Thus, even on the supposition that nonbelievers outnumber believers among those who are best positioned to judge whether God exists, there is no straightforward inference from that supposition to the insignificance of the datum. Of course, there are obvious disanalogies between the case of religious belief and examples like URN and Who Wants to Be a Millionaire? Among the most important is this: in the latter cases, but not in the former, individuals arrive at their opinions independently of one another. Thus, in the case of the game show, members of the studio audience do not consult with one another (or anyone else) before registering their opinions; the opinion that emerges as dominant is thus the result of an independent convergence. Similarly, in cases like URN, it is assumed that everyone arrives at his original estimate on the basis of his own observations. However, that feature seems to be conspicuously absent in the case of religious belief. This suggests a second strategy for minimizing the significance of the datum.

(ii) The datum is relatively insignificant, because the strong supermajority was not produced by independent convergence.

Recall our example from above: the fact that most of the group thinks that the correct answer is ' 138 ' is impressive evidence if each person arrived at that answer independently, but not if they did so by copying from a single member of the group. Indeed, in the latter case, the numbers count for nothing: the evidence supplied by the fact that many think that the answer is 138 is no stronger than the evidence provided by the fact that that was the answer arrived at by the individual from whom the others copied. More generally, impressive evidence that a given view is correct is afforded when

\footnotetext{
${ }^{26}$ More exactly, the expert-friend had a roughly 65 percent accuracy ratio, while the studio audience chose the right answer 91 percent of the time. See Surowiecki (2003): 4.
} 
a significant number of people independently converge on that view; on the other hand, the less their convergence is an independent matter, the less impressive it is as evidence. ${ }^{27}$

A critic might argue that this fact undermines the evidential value of the datum. Such a critic might very well concede that if billions of religious believers had arrived at their shared belief independently, this would be impressive evidence that it is true, but then point out that we know that nothing remotely like this actually occurred. In the case of the actual history of religious belief, what we find is not independent convergence but rather a convergence that is largely due to mutual influence and influence by common sources. In this respect, the case of religious belief is akin to a case in which students arrive at the same answer by copying from someone they trust. After all, no one thinks that the intellectual case for Islam would be any stronger if birthrates in Muslim countries had been twice as high in past decades as they actually were; nor would the case be any weaker if such birthrates had been significantly lower.

In my judgment, this is the best objection to the claim that the datum provides significant evidence for religious belief. I think that the proponent of the common consent argument should concede straightaway that the datum has significantly less evidential value than it would have had, had the same supermajority come about as a result of independent convergence. Indeed, classical proponents of the argument seemed to recognize the importance of independence, at least implicitly. For they often made much of the fact that something recognizable as religious belief was common not just among 'civilized peoples' but had also been discovered among relatively isolated populations. ${ }^{28}$

\footnotetext{
${ }^{27}$ On the importance and nature of independence, see especially the illuminating discussion in Goldman (2001): 150-156.

As Hartry Field pointed out to me, the need to discount the numbers is not limited to cases in which there is causal dependence present, as in the examples considered above. If I know that two individuals will respond to given evidence in the same manner, then I should treat their having arrived at some particular answer as one piece of evidence, and not two pieces of evidence, in favor of that answer (even if their both having arrived at that answer is in no way underwritten by some causal link).

${ }^{28}$ This led to various heated controversies, among anthropologists and others, as to whether the populations in question really did believe in God, or whether this was a projection of those who had first 'discovered' them. For a flavor of this, see Joyce (1923): 179-198.
} 
I believe that this is generally the right approach for a defender of the argument to take: while conceding the importance of independence, and acknowledging the large role that dependence plays in the case of religious belief, she should resist the assimilation of the religious case to cases like that involving the copied answer. Here, in addition to emphasizing the significant measure of independence in the case of religious belief (a significant number of groups that were relatively isolated from one another nevertheless arrived at the same belief), the defender of the argument should also appeal to the impressive persistence of religious belief, without which the strong supermajority would not obtain. Even in cases in which individuals initially acquire some belief from a common source, there is for each person the possibility of later abandoning it in the light of subsequent experience or reflection. In the case of religious belief, however, sufficiently many individuals do not do this that the strong supermajority persists over time. $^{29}$

Here we note one of the many places where, unsurprisingly, one's views about the significance of the datum will be influenced by one's views about the way in which religious convictions tend to be held. If one thinks, as some do, that religious believers are generally unreflective and uncritical (at least so far as their religious convictions are concerned), then one will be unimpressed with the fact that so many religious believers

${ }^{29}$ Compare: it is extremely plausible that the best explanation of the fact that $2+2=4$ is universally believed invokes the fact that this proposition is obviously true; here seems like a clear case in which an explanation that includes the truth of the proposition believed (however exactly that explanation is filled out) dominates those potential explanations that do not mention the truth of the proposition. However, notice that people do not typically learn even the most elementary truths of arithmetic autonomously; rather, they are taught such truths by parents, teachers, or others who already believe the truths in question. So in that sense, there is a significant lack of independence in this case as well. Nevertheless, the fact that people are originally taught elementary mathematical truths by authority figures does not account for why these truths continue to strike them as true. And here, it seems that no explanation that does not entail the fact that these claims are true could possibly be adequate to account their seeming true to so many people over time. My suggestion is that the proponent of the common consent argument should also appeal to the (admittedly much less impressive) persistence of religious belief as something that stands in need of explanation, and that is not accounted for by the fact that believers often acquire their beliefs from others who already hold them. 
retain their religious beliefs once having acquired them. On this view, cases in which theistic belief is acquired early on in life and is thereafter retained are no more surprising than cases in which a schoolboy who copies an answer early on during an exam ultimately submits that same answer with the rest of his exam at the end of the period. On the other hand, if one takes a more charitable view of the way in which many religious believers hold their convictions, then the persistence of such belief does call out for explanation.

In this context, the defender of the argument should also point out that the traditional anti-theistic project of providing a fully naturalistic, debunking explanation of religious belief similarly seems to presuppose that there is something left over that calls out for explanation, even after all of the facts about belief dependence have been taken into account. In this respect, Marx, Freud, and the proponent of the common consent argument are bedfellows, albeit exceedingly strange ones. After all, if the correct account of why $80 \%$ of the class came up with the same answer is simply that they copied that answer from a particular student, then there is obviously no need to provide an additional interesting story about why so many students found that answer so tempting or appealing. The same point holds in the case of religious belief: if lack of independence is enough to account for the distribution of opinion that we actually find, then there is no need to provide any additional interesting explanation in terms of wish fulfillment (Freud), consolation for the material hardships of this world (Marx), or truth (the proponent of the common consent argument).

(iii) The datum is actually false.

The most radical strategy for minimizing the significance of the datum is to simply deny that it is true: that is, one might simply deny that a strong supermajority of the world's population genuinely believes that God exists. More modestly, the critic of the argument might argue that we do not know whether the datum is true, or that we lack strong evidence to think that it is.

This might seem like an unpromising line of resistance. After all, that believers greatly outnumber non-believers is generally conceded by both camps, as well as by both 
those who find this putative fact depressing and those who find it cheering. Nevertheless, legitimate questions can certainly be raised about the quality of our grounds for supposing that this is the actual distribution of opinion. Here I have in mind not only the daunting practical difficulties inherent in any attempt to arrive at a reasonably accurate estimate of 'what the world thinks' about any question, or even the special difficulties that attach to this particular case (e.g. the fact that in many parts of the world, there will be extremely strong incentives for people to misrepresent their true views on this particular issue). Rather, I also have in mind certain more philosophically interesting reasons for doubt, reasons that would remain even if we knew with certainty that a strong supermajority of the world's population would sincerely profess religious belief if given the chance. Consider two such reasons for doubt.

First, I have taken for granted throughout this paper that (e.g.) devout Muslims and Christians, despite their deep theological differences, nevertheless share a particular belief that distinguishes them from atheists and agnostics. This assumption seems safe so long as we assume that 'God' (and its translations in other languages) functions semantically like an ordinary proper name. For on the best account of proper names that we possess (Kripke 1980), the reference of a name can be preserved even across radical differences in what is believed about the bearer of the name. Thus, a Muslim might convert to Christianity (or vice versa) and in doing so change her theological beliefs radically, while nevertheless continuing to believe, of one and the same divine being, that it exists. ${ }^{30}$

However, Mark Johnston (2009) has recently argued, with a great deal of both philosophical and theological sophistication, that 'God' (as well as its standard

${ }^{30}$ Compare the way in which, on the Kripke-Putnam account of natural kind terms, a scientist can change her theory of the electron radically, while nonetheless continuing to refer to one and the same microphysical particle by using the word 'electron' throughout this process. After the scientist has come to accept the new theory, she will think that her past self held a radically false theory about the entity of which she now has a true (or at least, better) theory; she will not think that her past self held a theory about something else, or nothing at all. Similarly, the religious convert, viewing things from the perspective of her new theological commitments, will think that her past theological commitments amounted to a radically false theory of the same person or entity of which she now has a better theory. 
translations into other languages) does not function semantically as a proper name. Rather, 'God' functions as a descriptive proper name or abbreviated title, neither of which tolerates nearly as much in the way of mistaken belief when it comes to the determination of reference. The upshot of this picture is to render problematic the idea that devout members of very different religious traditions really do 'ultimately worship the same God', or genuinely share some common belief in the deity. But to call this into question is to call into question the idea that atheists and agnostics lack some particular belief that the rest of the world shares. ${ }^{31}$

But let us set this possibility aside and simply assume the standard view according to which believing Christians, Muslims and Jews (etc.) share a common belief that they do not share with atheists and agnostics. Still, one might question just how common fullfledged theistic belief really is, even among those who would sincerely profess such belief. It is sometimes noted that, given what would seem to be the truly vast differences in world view between theists and atheists, many self-professed atheists and theists behave remarkably similarly in most contexts, including many contexts in which one would expect their putative differences to be manifest. Moreover, it is sometimes argued, with some plausibility, that in many such contexts (e.g., funerals) the behavior exhibited by members of both camps more closely resembles the behavior that one would have expected (at least a priori) from an atheist as opposed to a theist. One might try to leverage these facts in an argument that, for all we know, genuine belief in God is much less common than is ordinarily supposed, even among those who would sincerely avow such belief. One who presses this line of thought can correctly point out that, even though the fact that an individual sincerely avows $p$ is excellent evidence that she believes $p$, it is nonetheless defeasible evidence, and certainly does not exhaust the considerations that are relevant to whether we are justified in attributing that belief to her. He will then claim

\footnotetext{
${ }^{31}$ As Johnston puts it: "Believing in God is not a mere psychological state. It is more akin to an achievement... That is why belief in God may be a much rarer thing than has been almost universally supposed" (2009): 29-30.
} 
that, in the case of theistic belief, we often enough do have grounds for not attributing full-fledged belief in God, even to those who would sincerely profess such belief. ${ }^{32}$

At first glance, this line of thought might seem no more plausible than that advanced by those mad-dog defenders of the common consent argument who insisted that belief in God really is universal, and that individuals who sincerely profess not to believe in God are self-deceived. However, the current line of thought is significantly more plausible than the latter. For the mad-dog defender of universal belief in God insists that anyone who sincerely professes atheism or agnosticism has a false belief about whether she believes in God. On the other hand, the proponent of the current line of thought insists, not that every sincere theist has a false belief about whether she believes in God, but only that the phenomenon is common enough to render the datum false. It is, of course, compatible with this hypothesis that there are some - indeed, many millions--of fullfledged believers.

For my part, I am inclined to believe that the datum is true, and that neither of the considerations raised in this section should lead us to abandon it. Nevertheless, I also believe that an adequate treatment of these issues would inevitably require the resolution of quite subtle questions in the theories of reference and belief attribution. If that is correct, then fully getting to the bottom of the common consent argument might very well require, not only further inquiry in epistemology, but also into the philosophies of language and mind. ${ }^{33}$

\footnotetext{
${ }^{32}$ For a recent, particularly lively presentation of the kind of doubt at issue here, see Rey (2006).

${ }^{33}$ An earlier version of this paper was presented at a joint Princeton-Rutgers philosophy of religion workshop in the Spring of 2008. I am grateful to the audience present on that occasion for feedback, to Dan Garber and Dean Zimmerman for organizing the workshop and inviting me to speak at it, and to the Departments of Philosophy and Religion at Princeton, the Rutgers Philosophy Department, and the Princeton Theological Seminary for their sponsorship of the event. Finally, I would like to thank Kelly Clark and Ray VanArragon for the invitation to write up those thoughts for the present volume.
} 


\section{References}

Chadwick, Owen (1990). The Secularization of the European Mind in the Nineteenth Century. (Cambridge, UK: Cambridge University Press).

Christensen, David (2007). "Epistemology of Disagreement: the Good News".

Philosophical Review 116 (2): 187-217

Earman, John (1992). Bayes or Bust. (Cambridge, MA: MIT Press).

Edwards, Paul (1967). "Common Consent Arguments for the Existence of God". In Paul Edwards (ed.) The Encyclopedia of Philosophy, vol.2 (New York: Macmillan Publishing): 147-155.

Egan, Andy and Elga, Adam (2005). "I Can't Believe I'm Stupid". In John Hawthorne (ed.) Philosophical Perspectives, vol.19: Epistemology (Oxford, UK: Blackwell Publishers): 77-93.

Flint, Robert (1877). Theism. (London)

Goldman, Alvin (2001). “Experts: Which Ones Should You Trust?" in Philosophy andPhenomenological Research, Volume 63, 2001.

Harman, Gilbert (1965). "The Inference to the Best Explanation", in The Philosophical Review 74: 88-95.

Hodge, Charles (1871). Systematic Theology (New York).

Hume, David (1757). The Natural History of Religion. (many editions after first publication).

Johnston, Mark (2009). Saving God: Religion after Idolatry. (Princeton, NJ: Princeton University Press).

Joyce, George Hayward, S.J. (1923). Principles of Natural Theology (New York: Longmans, Green and Co.).

Kelly, Thomas (2005). “The Epistemic Significance of Disagreement”. In Tamar Szabo Gendler and John Hawthorne (eds.) Oxford Studies in Epistemology, vol.1 (Oxford: Oxford University Press): 167-196.

Kelly, Thomas (2010). "Peer Disagreement and Higher Order Evidence". In Richard Feldman and Ted Warfield (eds.) Disagreement. (Oxford: Oxford University Press). 
Kelly, Thomas (forthcoming a). "Following the Argument Where It Leads".

Kelly, Thomas (forthcoming b). "Disagreement and the Burdens of Judgment". In David Christensen and Jennifer Lackey (eds.) xxxx. (Oxford: Oxford University Press).

Kelly, Thomas (manuscript). Believing with Reason.

Kreeft, Peter, and Tacelli, Ronald (1994). Handbook of Christian Apologetics. (Downers Grove, IL: Intervarsity Press).

Kripke, Saul (1980). Naming and Necessity. (Cambridge, MA: Harvard University Press).

Kuhn, Thomas (1962). The Structure of Scientific Revolutions. (Chicago, IL: University of Chicago Press).

Locke, John (1689). An Essay Concerning Human Understanding. (many editions).

Lipton, Peter (1991). Inference to the Best Explanation (London, UK: Routledge).

Mackie, J.L. (1982). The Miracle of Theism. (Oxford: Oxford University Press).

Mercier, Cardinal Joseph (1926). A Manual of Modern Scholastic Philosophy. English translation by T.L. and S.A. Parker (London).

Mill, John Stuart (1885). “Theism”. Reprinted in Three Essays on Religion (Amherst, NY: Prometheus Books, 1998.) Page numbers are to the reprint.

O’Briant, Walter H. (1985). "Is There an Argument Consensus Gentium?" In the International Journal for Philosophy of Religion 18:73-79.

Plato. Laws (many editions).

Putnam, Hilary (1975). Mathematics, Matter, and Method: Collected Papers vol.1 (Cambridge: Cambridge University Press).

Quinn, Philip L. and Taliafferro, Charles (ed.) (1997). A Companion to Philosophy of Religion. (Blackwell: Malden, MA).

Rey, Georges (2006). "Does Anyone Really Believe in God?," in D. Kolak and R. Martin (eds.) Experience of Philosophy, 6 ed., (Oxford: Oxford University Press): 335353.

Sobel, Jonathan Howard (2003). Logic and Theism (Cambridge, UK: Cambridge University Press). 
Sorensen, Roy (1988). Blindspots. (Oxford, UK: Oxford University Press).

Surowiecki, James (2004). The Wisdom of Crowds. (New York: Doubleday).

Swinburne, Richard (1979). The Existence of God. (Oxford: Oxford University Press).

Wainwright, William J. (2005). The Oxford Handbook of Philosophy of Religion.

(Oxford: Oxford University Press).

White, Roger (2005). "Explanation as a Guide to Induction”, Philosophers' Imprint 5 (2): $1-29$.

Zuckerman, Phil (2006). "Atheism: Contemporary Rates and Patterns" in Michael Martin (ed.) The Cambridge Companion to Atheism (Cambridge, UK: Cambridge University Press): 47-68. 